\title{
Proximate Determinants of Declining Fertility in Oman in the 1990s
}

\author{
M. Mazharul Islam \\ Department of Mathematics and Statistics \\ Sultan Qaboos University (Sultanate of Oman) \\ mmazharul@yahoo.com \\ Atsu S.S. Dorvlo \\ Department of Mathematics and Statistics \\ Sultan Qaboos University (Sultanate of Oman) \\ Ahmed M. Al-Qasmi \\ Directorate General of Planning \\ Ministry of Health (Sultanate of Oman)
}

\begin{abstract}
The current fertility rate in Oman declined dramatically from a very high rate of 8.6 births per woman in 1988 to 4.8 births per woman in 2000, a decline of nearly four births per woman or a decline of 44 percent of total fertility over a period of twelve years. This decline has occurred in the absence of any official national level family planning programme. Using recent national level survey data and the Bongaarts framework of the proximate determinants of fertility, in this study an attempt has been made to identify the factors responsible for such remarkable decline in fertility in Oman. The results indicate that a decrease in the age-specific proportions of women who are married, followed by an increase in contraceptive use are the most important mechanisms by which fertility has declined in Oman. Women education and employment are likely factors that encourage couples to delay marriage and use modern family planning methods and thus reduce marital fertility.
\end{abstract}

Keywords: Oman, fertility, proximate determinants, postpartum infecundability.

\section{Résumé}

Le présent taux de fertilité en Oman baissa de maniére dramatique d'un très haut taux de 8.6 naissances par femme en 1988 à 4.8 naissances parfermme en 2000, soit une baisse de prés de quatre naissances par femme ou une baisse, de 44 poucent de fertilité totale sur une durée de douze ans. Cette baisse est passée en l'absence de planisme familial official au niveau national. Utilisant les informations d'une enquête nationale et récente et le systéme de reference Bongaarts sur les déterminants de la fertilité, une tentative a été faite pour identifier les facteurs responsables d'une telle baisse de fertilité en Oman. Les résultats ont indiqué qu'une baisse dans les proportions d'âge des femmes marriées, suivi par une hausse dans l'usage des contraceptifs sont les facteurs les plus importants à partir desquels la fertilité a décliné en Oman. L'éducation des femmes et l'emploi sont des facteurs vraisemblables qui encourage les couples à retarder le mariage et à utiliser les méthodes modernes de planisme familial, ce qui réduit la fertilité matrimoniale.

Mots-clés : l'Oman, la fertilité, les déterminants proches, infecundability postpartum. 


\section{Introduction}

Like most of the Middle Eastern and Arab countries, Oman is a high fertility country (about 5 births per woman) with a high population growth rate (about 2 percent per annum). The government of Oman considers the current fertility rate to be high, but would like to maintain it (Sulaiman et al. 2000). There is no official population policy in Oman. Contraceptive use rate is also low (32 percent; Al-Riyami 2000). Nevertheless, Oman has experienced dramatic decline in period fertility rates in recent times. The total fertility rate (TFR), which was more than 8 births per woman in the late 1980s, declined to about 5 births per woman in 2000 (Sulaiman et al. 1992, 2000; Eltigani 2001a, 2001b). On the other hand, infant mortality has declined from a very high rate of 140 per 1,000 in the early seventies to 14 per 1,000 in the mid-nineties (UNDP 1998). In a pro-natalist country like Oman, where there is no official population policy, the rapid decline in fertility by more than 3 births per woman in just over one decade might be interesting for other high fertility countries. In a recent study, Erfani and McQuillan (2008) also noted a similar pattern of fertility decline in Iran, where a population policy has been in place for many years.

According to the modern theory of fertility transition, it is widely argued (though with a lack of uniformity) that socioeconomic development arising from modernization precedes fertility declines (UN 1961; Freedman 1979; Simmons 1985). Modernization includes urbanization, industrialization, social mobility, change in women's status (through education, income earning opportunity outside the home, role in society, decision making power, etc.), reduction in infant and child mortality, institutionalized the old age support, and better living standards. Although higher total fertility is a known attribute in the poorest countries, many wealthy and middle-income countries in the Middle East and the Arab world, such as Saudi Arabia, also have a comparably high fertility (Tabutin and Schoumaker 2005). On the one hand, rapid declines in fertility have taken place among many relatively poor countries in the region, such as Egypt, Syria, and Morocco (Tabutin and Schoumaker 2005). In many developing countries in Asia and Africa, fertility has declined close to replacement level without much socioeconomic development. On the other hand, countries at similar levels of economic development are often seen to display very different patterns of fertility behaviour (Bongaarts and Watkins 1996). Cleland et al. (1994) stated that past declines in the level of fertility across these countries were mainly attributed to a strong family planning program, in the absence of any remarkable change in socioeconomic status in a fundamentally traditional and impoverished society. Recently Caldwell et al. (1999) questioned the validity of such remarks and argued that change in other sectors of society and the economy might also play an important role. These two opinions remind us of the old debate that took place during the first International Conference in Bucharest in 1974. In that conference, developing countries were in favour of "development as the best contraception," while the developed countries argued for an intensive family planning program. The debate is still going on. Thus, the relationship between fertility and its determinants is very complex, and studying the determinants of fertility at the macro level is not an easy task, because human reproduction is an outcome of biological and behavioural factors, on the one hand, and cultural and socioeconomic factors, on the other (Bongaarts and Potter 1983). 
The principal characteristic of biological and behavioural factors is that they can influence fertility directly, while socioeconomic and environmental factors affect fertility through modification of one or more biological or behavioural factors. If a biological or behavioural factor-such as contraceptive use-changes, then fertility necessarily changes also, though this is not necessarily the case for a socioeconomic determinant such as education. Bongaarts (1978) in his classical paper termed the biological and behavioural factors as proximate determinants of fertility, since they directly affect fertility; and all other social, economic and environmental factors affect fertility through these variables. Using data from 41 developed and developing countries, Bongaarts and Potter (1983) further observed that 96 percent of the variance in the total fertility rates of these populations could be explained by the four principal proximate determinants of fertility: namely marriage, contraception, lactational infecundability, and induced abortion. Because of these findings, the analysis of the determinants of fertility becomes more simplified, focusing only on these four variables. To quantify the fertility inhibiting effects of the four principal proximate determinants, Bongaarts (1978) developed a framework that is now widely used in fertility analysis.

To improve our understanding of the causes of fertility decline in Oman, it is necessary to analyze how proximate determinants influence fertility. Keeping this in view, this paper analyzes the levels and trends of the proximate determinants of fertility in Oman. The study provides a critical review of the major proximate determinants of fertility, and estimates their fertility-inhibiting effects using the Bongaarts model. We use the Bongaarts framework to identify the relative contribution of changes in each of the different proximate determinants to the decline in total fertility.

Although there is some agreement on the social and economic factors that influence fertility decline (Erfani and McQuillan, 2008), to our knowledge, there has been no empirical study on how these factors influenced the proximate determinants of fertility in Oman due to dearth of reliable data in the past. The availability and accessibility of recent national level survey data such as the 1995 Oman Family Health Survey (OFHS) and the 2000 Oman National Health Survey (ONHS) enable us to study the causes of fertility decline in Oman.

\section{Background}

The Sultanate of Oman is a country on the southeast coast of the Arabian Peninsula in Southwest Asia, with a total area of 309,500 square kilometres. The Sultanate is bordered by the United Arab Emirates to the northwest, the Kingdom of Saudi Arabia to the west, the Republic of Yemen to the southwest, the Hormoz Strait to the north, and the Arabian Sea to the east. The country is composed of varying topographic areas, consisting of plains (about 3 per cent), mountain ranges with granite and limestone (15 per cent area), and the remaining area (82 per cent) is mainly desert and wadis (dry river beds; Sulaiman et al. 2000). Oman's climate is hot and dry in the interior and humid along the coast.

The country has had a turbulent past, characterized by internal tribal strife throughout the 19th and early 20th centuries. Modernization began in the late 1960s with the commercial exploitation of oil and natural gas, and thereby increased government revenues. In recent years, massive economic and social developments are 
taking place in Oman. The present Government of Oman, aided by the oil export revenues, is implementing various economic and social development programmes. Prior to the commercial exploitation of oil in the late 1960s, the economy of Oman consisted of subsistence agriculture and fishing. Social and economic infrastructure was almost non-existent. By the late 1980s, Oman was transformed into a modern state, with all the modern facilities and infrastructures. The standard of living has improved enormously since the mid-1970s. Urbanization is profoundly changing the spatial distribution of the population. Intensive migration, mainly from rural to urban areas and from the interior to more developed areas, is important in shaping the contemporary social structure of the Omani population.

The political stability that has been established in Oman over the past 40 years has enabled the authorities to design and implement a successful and wide-ranging modernization program that has influenced all aspects of life of the Omani people (Eltigani 2001b). As part of the modernization drive, the government of Oman has put much emphasis on the expansion of education to both males and females. As a result, the net enrolment rate for females aged 6-10 has increased from 5 percent (Zurayk 1979) in the 1970s to 92 percent in the mid-1990s, and the gender gaps in education at all levels has been reduced. In recent times, due to the increase in women's education and social status in Oman, women's control over their own reproductive lives has increased (Al-Riyami and Afifi 2003). This would clearly have a major impact on fertility, as well as on the health of mothers and the growth and survival of their children.

According to the preliminary results of the third and latest population Census in Oman, which was conducted in December 2010, the total population of Oman is about 2.7 million, of which 27 percent are non-Omanis (www.census.gov.om). Nearly one-fifth of the total population lives in the vast rural areas, and nearly 5 per cent of the population lives in mountains and other hilly areas, where rugged terrain impedes the provision of healthcare and basic services. The crude birth rate was estimated at 27.3 per thousand population, the crude death rate at 3.3 per thousand, and the population growth rate at 2.0 percent since last census in 2003 (Ministry of Health 2009).

Figure 1 is a population pyramid showing the age-sex distribution of the total population (combining Omani and non-Omani) population, Omani population, and non-Omani population. There is a huge imbalance in the age-sex structure of the total population, with large numbers of young men as a result of high levels of young migrant workers, mainly from Asia. However, the age-sex structure of the Omani population is more or less balanced.

Sociocultural life in Oman is structured around the family and is linked to traditional and religious teachings that consider family formation to be the basic function of the society. The family is the unit in which reproduction is authorized and is expected to occur through marriage. Marriage and establishing a family are treated as essential and sacred. In the past, the main and the most important roles of women were to bear and raise children. Today, this is still central, but has been modified somewhat given the increasing participation of women in higher education and in the paid labor force.

Socioeconomic changes, which are likely to carry on in the near future, have had profound effects on individuals' lives. These various macro societal changes 


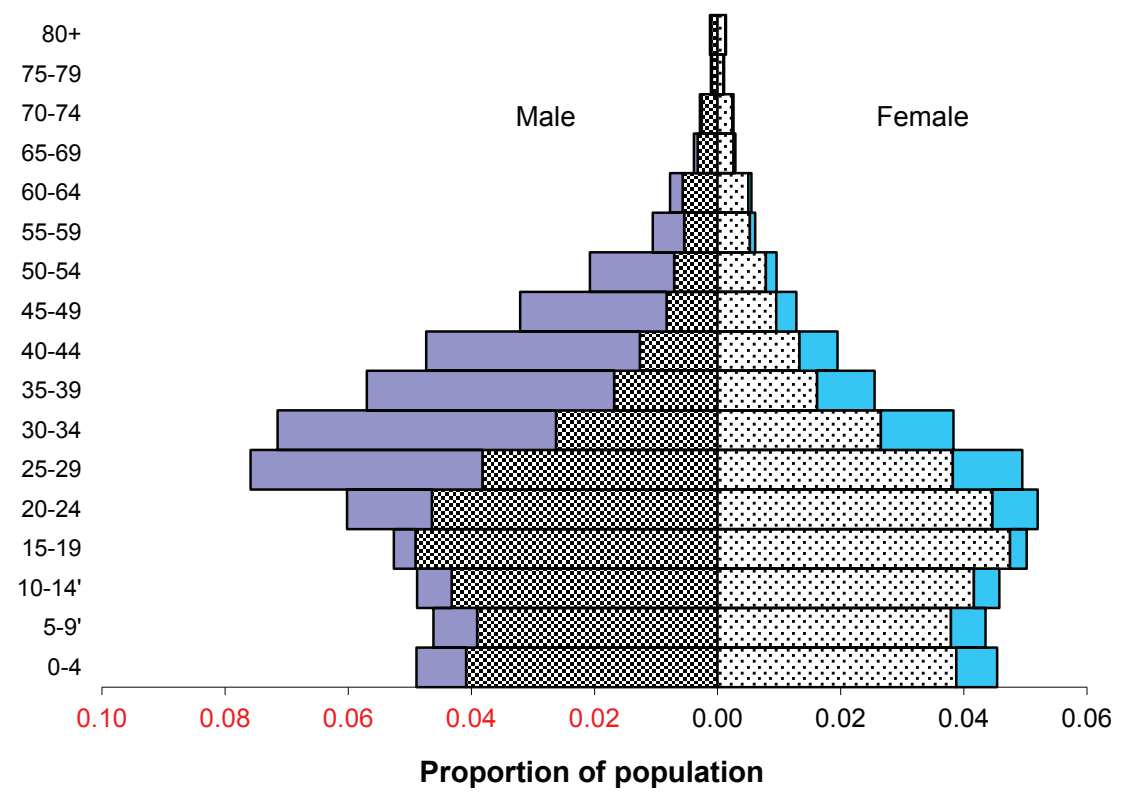

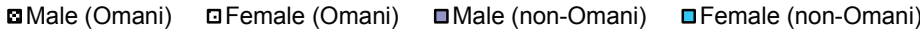

\section{Figure 1. Population pyramid showing the age-sex structure of total, Omani and non-Omani population, Oman 2008.}

have exerted an impact on fertility behaviour and health status. Recent nationallevel survey data indicated a remarkable increase in age at first marriage and modern contraceptive use. As a result, Oman is passing through a critical phase of demographic transition.

Despite the recent decline in fertility, Oman is still a high-fertility country and is passing through the early stages of demographic transition. The age structure indicates a very young population, with more than 30 percent below age 15 , thus having a high potential for future population growth. Persistent high fertility and a considerable decline in mortality will result in high population growth in Oman. According to the United Nations population estimates and projections, the population of Oman will increase to 5.4 million by 2025 (UN 2000).

The underlying demographic transition is likely to give rise to two distinct changes in age structure of the population: first, the population of working age will grow rapidly; later, the number of older adults will increase rapidly. All these changes in population structure are known as demographic bonus or demographic dividend. The demographic bonus or dividend arises when society is at a middle phase and dependency ratios are low. On the other hand, due to the demographic transition, new challenges will emerge in Omani society. There will be an increase in the working-age population (aged 15 to 59), which will create pressure to generate new employment. The rise in labor force participation of women will also be considered as a result of declining fertility, as women will need to spend less time in bearing and rearing of children. The population aged 60 or more will necessarily expand, in relative and absolute numbers. As a result of this, age-related government expenditures will increase considerably and will cause an increment in the 
fiscal deficit. The growing bulge of unemployed young people has serious political ramifications for many Middle Eastern regimes, including Oman. The consequences of these demographic transitions are evident today, but they will become even more pronounced in the coming years.

\section{Data}

Oman has limited sources of demographic data for the analysis of population dynamics. The first population census of Oman was conducted in 1993. The 1988/89 Oman Child Health Survey provided the first national-level survey data on health and population, followed by the 1995 Oman Family Health Survey (OFHS 1995) and the 2000 National Health Survey (ONHS 2000). This study utilizes data extracted from both the OFHS 1995 and the ONHS 2000. The details of these two surveys may be seen, respectively, in Sulaiman et al. (2000) and Al- Riyami et al. (2000). Both the surveys were conducted by the Ministry of Health of the Government of the Sultanate of Oman, with the collaboration of the UN Organizations such as UNFPA and UNICEF, WHO, and the UN Statistics Division. The surveys considered the households of Omani nationals only. Ever-married women under 50 years of age were considered as eligible respondents.

The OFHS-95 covered a nationally representative sample of 6,103 Omani households, while the ONHS 2000 covered 2,013 Omani households. From the selected households, 6,405 and 2,037 eligible women were successfully interviewed in the two surveys, respectively.

The OFHS 1995 is comparable to the standard Demographic and Health Surveys (DHSs), while the ONHS 2000 is not as comprehensive as DHSs in terms of the number of variables and sample size. However, it contains a wide ranging data on general health and reproductive health characteristics of household members including birth history data, which allow detail fertility analysis. The ONHS 2000 lacks data on household economic variables. The Ministry of Health of Oman made these data sets available for the current study.

\section{Model and model index estimates}

To measure the fertility inhibiting effects of the four principal proximate determinants of fertility in a given population, Bongaarts (1978) and Bongaarts and Potter (1983) have developed an aggregate model on the basis of observation that with the presence of inhibiting effects of all proximate determinants, a population's actual level of fertility is measured by the total fertility rate (TFR), while in the absence of inhibiting effects of the proximate determinants, the fertility level of the population could reach a hypothetical maximum level, called total fecundity rate $(\mathrm{TF})$. Thus, the observed level of fertility in a given population reflects the extent to which the proximate determinants reduce the TF. For most populations, TF falls between 13 and 17 births per woman, with an average of 15.3 (Bongaarts 1978). The fertility-inhibiting effects of the four principal proximate determinants-proportion married, contraception, induced abortion, and postpartum infecundability - are measured in the model by four indices: $C_{m}=$ index of marriage, $C_{c}=$ index of contraception, $C_{a}=$ index of induced abortion, and $C_{i}=$ index 
of post-partum infecundability. The value of each index lies between 0 and 1, 0 signifying complete fertility inhibition and 1 meaning no fertility inhibition. The complement of the value of an index is the proportionate reduction in fertility due to the inhibiting effect of that proximate variable. The relationship between the actual level of fertility in a population, as measured by total fertility rate (TFR) and the biological maximum TF, is, then, obtained as:

$$
\mathrm{TFR}=C_{m} \times C_{c} \times C_{a} \times C_{i} \times \mathrm{TF}
$$

Because of legal constraints as well as social sensitivities, no direct information on the practice of abortion is available from any of the national-level surveys in Oman. Questions on the practice of abortion were included in both the 1995 OFHS and 2000 ONHS surveys, but the response rate was very negligible (only 9 abortion cases were reported in the 2000 ONHS). Due to lack of data on abortion in Oman, the index of induced abortion $\mathrm{Ca}$ is assumed to be 1 in this application. Erfani and McQuillan (2008) also observed a similar situation in Iran.

\section{Estimation of the Index of Marriage $C_{m}$}

The index of marriage $C_{m}$ is estimated as the weighted average of the agespecific proportions of female currently married $m(a)$, with the weights provided by the age-specific marital fertility rates $g(a)$, where $a$ is the age or age group (Bongaarts and Potter 1983: 81). The value of $C_{m}$ is the proportionate reduction of fertility due to the proportion of women of childbearing age who are not married. Thus,

$$
C_{\mathrm{m}}=\frac{\mathrm{TFR}}{\mathrm{TMFR}}=\frac{\sum m(a) \times g(a)}{\sum g(a)}
$$

\section{Estimation of Index of Contraception $C_{c}$}

The effect of contraception on the risk of conception is measured by the index $C_{c}$. The value of the index equals 1 if there is no conctraception and 0 if all fecund women use a fully effective method. The index is calculated (Erfani and McQuillan 2008) as

$$
C_{c}=1-1.08 \times u \times e
$$

where $u$ is the current contraceptive prevalence rate CPR and $e$ is the average useeffectiveness of contraception, which is calculated as the weighted average of the following method-specific use-effectiveness levels:

\begin{tabular}{lc}
$\begin{array}{c}\text { Contraceptive methods } \\
\left(\mathrm{u}_{\mathrm{m}}\right)\end{array}$ & $\begin{array}{c}\text { Use-effectiveness } \\
\left(\mathrm{e}_{\mathrm{m}}\right)\end{array}$ \\
\hline Pill & 0.90 \\
Condom & 0.62 \\
IUD & 0.95 \\
Injection & 0.99 \\
Sterilization & 1.00 \\
Others & 0.70 \\
\hline Source: Bongaarts (1982).
\end{tabular}


Thus, $u=\sum u_{m}$ and $e=\sum u_{m} \times e_{m} / u$

Since estimates of the method-specific use-effectiveness level $e_{i}$ are difficult to obtain, and no such study has been done in Oman, the above estimates of $e_{i}$ are adapted from data from the Philippines, as suggested by Bongaarts (1982) for use in developing countries.

\section{Estimation of the Index of lactational infecundability $C_{i}$}

The index of postpartum infecundability $C_{i}$ measures the effects of postpartum amenorrhoea and lactation (breastfeeding) on fertility (Erfani and McQuillan 2008). As postpartum infecundability does not influence the duration of the reproductive years, its effect on fertility operates entirely through modification of the birth interval. The index, therefore, equals the ratio of the average birth interval in the absence and in the presence of postpartum infecundability. In the absence of postpartum infecundability, the birth interval averages about 20 months, the sum of 1.5 months of post-partum anovulation, 7.5 months of waiting time to conception, 2 months of time added by spontaneous intrauterine mortality and 9 months of full-term gestation. In the presence of postpartum infecundability, the average birth interval equals 18.5 months $(=7.5+2+9)$ plus $i$, the average duration of postpartum infecundability (Bongaarts and Potter 1983: 86). Thus

$$
C_{i}=20 /(18.5+i)
$$

The OFHS-95 and ONHS 2000 lack direct estimates of the duration of postpartum infecundability. However, an indirect estimate of the duration of postpartum infecundability can be obtained from the duration of breastfeeding using the following fitted model relating breastfeeding and post-partum infecundability:

$$
i=1.753 e^{0.1396 \times B-0.001872 \times B^{2}}, \quad R^{2}=0.96
$$

where $i$ is the average duration of post-partum infecundability and $B$ is the average duration of breastfeeding. The fitted model is adopted from Bongaarts and Potter (1983).

\section{Results}

\section{Levels and Trends in Fertility}

Table 1 presents the levels and trends in age-specific fertility rate (ASFR) per 1,000 women and total fertility rate (TFR) per woman in Oman during 1988 to 2000. These pieces of information are obtained from the three national-level surveys. The results show that the total fertility rate declined from 8.6 births per woman in 1988 to 4.8 births per woman in 2000 — a decline of 3.8 births per woman over a short period of 12 years. In other words, fertility has declined by 44 percent in 12 years, or an average of 3.7 percent per year between 1988 and 2000. This is a huge decline in fertility over a short period of time. The pace of decline was steeper during the late 1990s. For example, within a period of seven 
years, starting from 1988 to 1995, fertility declined by 1.5 births per woman, or 18 percent (2.6 percent per year), while for the following five-year period (1995 to $2000)$, it declined by 2.25 births per woman or 32 percent ( 6.4 percent per year).

Table 1. Age-specific fertility rates (ASFRs) per 1000 women and total fertility rates (TFR) from different surveys, Oman 1988, 1995, 2000.

\begin{tabular}{|c|c|c|c|c|c|c|c|c|c|}
\hline \multirow{3}{*}{$\begin{array}{l}\text { Age } \\
\text { group }\end{array}$} & \multicolumn{2}{|c|}{$1988^{1}$} & \multicolumn{2}{|c|}{$1995^{2}$} & \multicolumn{2}{|c|}{$2000^{3}$} & \multicolumn{3}{|c|}{$\%$ change } \\
\hline & & Relative & & Relative & & Relative & & & \\
\hline & ASFR & $\begin{array}{c}\% \text { of } \\
\text { ASFR }\end{array}$ & ASFR & $\begin{array}{c}\% \text { of } \\
\text { ASFR }\end{array}$ & ASFR & $\begin{array}{c}\% \text { of } \\
\text { ASFR }\end{array}$ & $\begin{array}{c}1989- \\
1995\end{array}$ & 2000 & 2000 \\
\hline $15-19$ & 220 & 12.8 & 86 & 6.1 & 15 & 1.5 & -60.9 & -82.6 & -93.2 \\
\hline $20-24$ & 383 & 22.3 & 270 & 19.1 & 143 & 14.8 & -29.5 & -47.0 & -62.7 \\
\hline $25-29$ & 382 & 22.2 & 332 & 23.5 & 237 & 24.5 & -13.1 & -28.6 & -38.0 \\
\hline $30-34$ & 323 & 18.8 & 300 & 21.3 & 231 & 23.9 & -7.1 & -23.0 & -28.5 \\
\hline $35-39$ & 251 & 14.6 & 222 & 15.7 & 174 & 18.0 & -11.6 & -21.6 & -30.7 \\
\hline $40-44$ & 117 & 6.8 & 114 & 8.1 & 95 & 9.8 & -2.6 & -16.7 & -18.8 \\
\hline $45-49$ & 43 & 2.5 & 86 & 6.1 & 73 & 7.5 & 100.0 & -15.1 & 69.8 \\
\hline TFR & 8.6 & 100.0 & 7.05 & 100.0 & 4.8 & 100.0 & -18.0 & -31.9 & -44.2 \\
\hline \multicolumn{10}{|c|}{ Mean age at child bearing: } \\
\hline & & 29.2 & & 31.1 & & 32.0 & & & \\
\hline
\end{tabular}

Sources: 1 Sulaiman et al. (1992), Table 11.13; 2 Sulaiman et al. (2000), Table 8.14, p.

120; 3 National Health Survey (2000), Table 3.14, p. 49.

The age-specific fertility rates indicate high fertility among Omani women over a broad peak extending over ages 20-39. Maximum fertility occurs among women ages 25-29 years, closely followed by women aged 30-34 (Figure 2). Analysis of the fertility rates by age cohort shows that starting from 1988 to 2000, fertility declined steadily in all age groups except 40-49 (Table 1 and Figure 3). The declines in fertility is steeper among young women aged 15-24. In 1988/89, 220 per 1,000 women aged 15-19 gave birth to a child in that year. By 2000 this rate had fallen to only 14 women per 1,000 in this age group. The decline was also sharp among women in their twenties. In 1988/89, 383 per 1,000 women aged 20-24 gave birth to a child. By 2000, this had reduced to less than one-third, i.e., 103 births per 1,000 women. The pattern of fertility decline for women in their thirties (30-39 years) is quite different from that for younger women (Figure 3). Fertility rate of these older women declined, but at a much more subdued rate than among younger women aged 29 and less. On the other hand, fertility rates among the oldest group of women aged 40-49 had increased over the period 1988 to 2000. For example, in 1988/89, 117 per 1,000 women gave birth to a child, which increased to 136 per 1,000 women in 2000 .

The relative contribution to total fertility by women under age 25 declined from 35 percent in 1988 to 16 percent in 2000; on the other hand, relative contribution to total fertility by women aged 25 and above increased substantially over the period. This indicates a shift in fertility towards higher age groups. The shift in timing in fertility to older ages is also evident from a rise in the mean childbearing age from 29 years in 1988 to 32 years in 2000. The relative increase in fertility among women aged 30 and over is nowhere near enough to compensate for the rate of decline among younger women. Between 1988/89 and 2000 the fertility rates dropped in all age groups except the age group 45-49, attesting to the fact that a substantial part of the change in fertility rates is due to fertility decline rather 


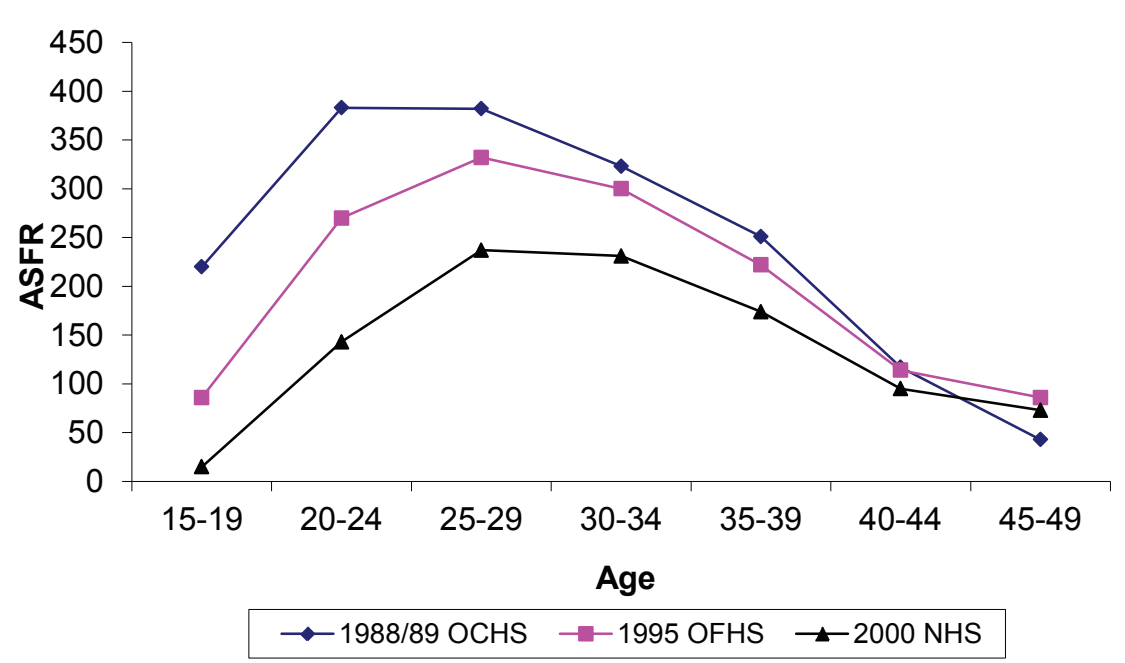

Figure 2. Age-specific fertility rates, Oman 1988/89, 1995, 2000.

than just fertility delay. In sum, whatever the exact level of current fertility, it can be argued that there is ample evidence that, during the last fifteen years, fertility in Oman declined by at least 40 percent. This decline can be attributed to the differential impact of many direct determinants of fertility, which are called proximate determinants, as well as indirect determinants.

\section{Role of Major Proximate Determinants in Fertility Decline}

The summary measures which are needed for the application of the model are presented in the first panel of Table 2. Owing to the unavailability of information on the sensitive issue of induced abortion, we assume an overall total induced abortion rate of zero and the value of the index $C_{a}$ as 1.00 . However, the impact of this is reflected in the model estimation of total fertility. The second panel of Table 2 presents the estimated values of the indices of the three principal

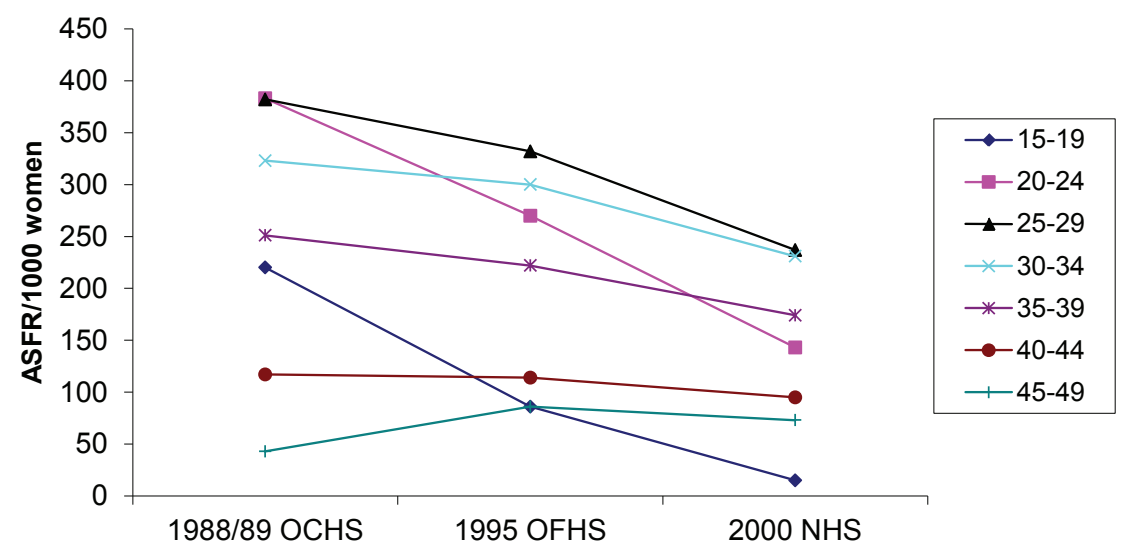

Figure 3. Trends in fertility rates for different age cohort, Oman 1988/89, 1995, 2000. 
proximate determinants of fertility. The complement of each index represents the proportionate reduction in fertility attributable to each fertility determinant. The lower the index value, the greater the fertility-reducing impact. Multiplying all of the indexes together by the total fecundity rate of 15.3 produces the predicted TFR for the population. The predicted TFR typically differs from the observed TFR because of underreporting of births, measurement errors of the proximate determinants, or the omission of proximate determinants that are influential in determining fertility levels in the population under study, such as induced abortion. However, this does not affect the analysis of the relative importance of the proximate determinants in reducing fertility.

Table 2. Reproductive measures and derived indices of proximate determinants, Oman 1995 and 2000.

Proximate determinants 1995 OFHS 2000 ONHS $\begin{gathered}\text { \% change during } \\ 1995-2000\end{gathered}$

A. Reproductive measures

TFR

TMFR
7.05 per woman 4.80 per woman

9.80 per woman 7.64 per woman

23.7 per cent 31.7 per cent

$0.87 \quad 0.87$

Mean Post-partum infecundability (i) 12.7 months 11.2 months

B. Model indices

$\begin{array}{lrrr}\text { Marriage }\left(C_{m}\right) & 0.72 & 0.63 & -12.50 \\ \text { Contraception }\left(C_{c}\right) & 0.78 & 0.70 & -10.26 \\ \text { Post-partum infecundability }\left(C_{i}\right) & 0.64 & 0.67 & 4.69 \\ \text { Abortion }\left(C_{a}\right) & 1.00 & 1.00 & 0.00 \\ \text { Combined effect of four determinants } & 0.359 & 0.295 & -17.82 \\ \quad\left(C_{\mathrm{m}} \times \mathrm{C}_{\mathrm{c}} \times \mathrm{C}_{\mathrm{i}} \times \mathrm{C}_{\mathrm{a}}\right) & & & \end{array}$

\begin{tabular}{lrr}
\hline Total fecundity (TF) & 15.30 & 15.30 \\
\hline Predicted TFR & 5.48 & 4.54 \\
\hline
\end{tabular}

The model indices show that the marriage pattern has the highest fertility reducing effect in 2000, accounting for 37 percent reduction of actual fertility levels below marital fertility $\left(C_{m}=0.63\right)$. Post-partum infecundability emerges as the second most important fertility-reducing factor in 2000, accounting for a 33-percent reduction $\left(C_{i}=0.72\right)$ in the total fecundity rate TF. Contraception has the lowest fertility reducing effect, accounting for a 30-percent reduction $\left(C_{c}=0.70\right)$ of natural fertility relative to marital fertility. In 1995, post-partum infecundability was the highest fertility reducing factor, followed by marriage and contraception. Results in Table 2 also document the change in the effects of the proximate determinants of fertility in Oman. During the period 1995-2000, both the marriage and contraception indices declined, by about 13 percent and 10 percent, respectively, while the index of post-partum infecundability increased by 5 percent. This implies that the fertility-inhibiting effects of marriage pattern and contraception are increasing, while decreasing for post-partum infecundability due to a decline in the duration of breastfeeding and post-partum abstinence. The combined effects of the three factors caused the reduction of fertility by at least 18 percent, and the 
reduction in fertility between 1995 and 2000 has been caused primarily by marriage pattern and contraception.

Table 3 exhibits the magnitude of the total inhibiting effect being accounted for by each proximate determinant at two points in time. The difference between the total fecundity (TF, taken as 15.3) and the predicted or model-estimated TFR (5.48 in 1995 and 4.54 in 2000) demonstrates the resultant inhibitory effect of each determinant. The total inhibiting effect is prorated by the proportion of the logarithm of each index to the sum of the logarithms of all indices (Wang et al. 1987). The results indicate that in 1995, out of 9.81 (=15.3--5.48) births being inhibited, 4.25 births (or 43 percent of total inhibiting effects) were due to the effect of post-partum infecundability, 3.15 births (or 32 percent) due to the marriage variable, and 2.41 births (or 25 percent) due to contraception. Similarly, in 2000 the three proximate variables inhibited 10.75 births — distributed, respectively, as 4.12 births (or 38 percent) by marriage, almost 3.5 births (or 33 percent) by postpartum infecundability, and 3.13 births (or 29 percent) by contraception. That is, the marriage pattern emerged as the number one predictor of the recent decline in period fertility rate in Oman, closely followed by the post-partum infecundability and contraceptive prevalence rate. Between 1995 and 2000, a change in marriage patterns occurred in Oman, resulting in substantial proportions of women of reproductive age living outside of marital unions. Contraceptive use also grew in Oman during this period.

Table 3. Magnitude of the total fertility-inhibiting effect being accounted for each proximate fertility determinants, Oman 1995, 2000.

\begin{tabular}{lrrrr} 
& \multicolumn{4}{c}{ Fertility-inhibiting effect } \\
\cline { 2 - 5 } \multicolumn{1}{c}{ Proximate determinants } & \multicolumn{3}{c}{$\begin{array}{c}\text { Reduction of births per } \\
\text { woman }\end{array}$} & Percentage reduction \\
\cline { 2 - 5 } & 1995 & 2000 & 1995 & 2000 \\
\hline Marriage & 3.15 & 4.12 & 32.11 & 38.29 \\
Contraception & 2.41 & 3.13 & 24.55 & 29.13 \\
Post-partum infecundability & 4.25 & 3.50 & 43.34 & 32.58 \\
\hline Total: [TF - TFR(est.)] & 9.81 & 10.75 & 100.00 & 100.0 \\
\hline
\end{tabular}

Note: The total fertility inhibiting effect is prorated by the logarithm of each index e.g. effect of marriage:

$$
[\text { TF-TFR(estimated) }] \times \log /\left(\log C_{m}+\log C_{c}+\log C_{i}\right) .
$$

Figure 4 (adopted from Erfani and McQuillan 2008) shows the age pattern of the fertility-inhibiting effects of marriage, contraception, and post-partum infecundability in 2000 in Oman. The estimates of the ASF(a) and ASNMF(a) are obtained using the age-specific version of the Bongaarts model, suggested by Bongaarts and Potter (1983). It is evident from Figure 3 that the fertility-inhibiting effect of marriage is most influential among young women aged 15-29 who delay marriage. Post-partum infecundability follows an age pattern similar to the effect of marriage. In contrast to the fertility-inhibiting effects of marriage and post-partum infecundability, contraception has a relatively smaller effect, which is almost identical for women in all reproductive age groups. Figure 4 shows that the reduction of fertility from the theoretical maximum levels (ASF) to the observed levels 


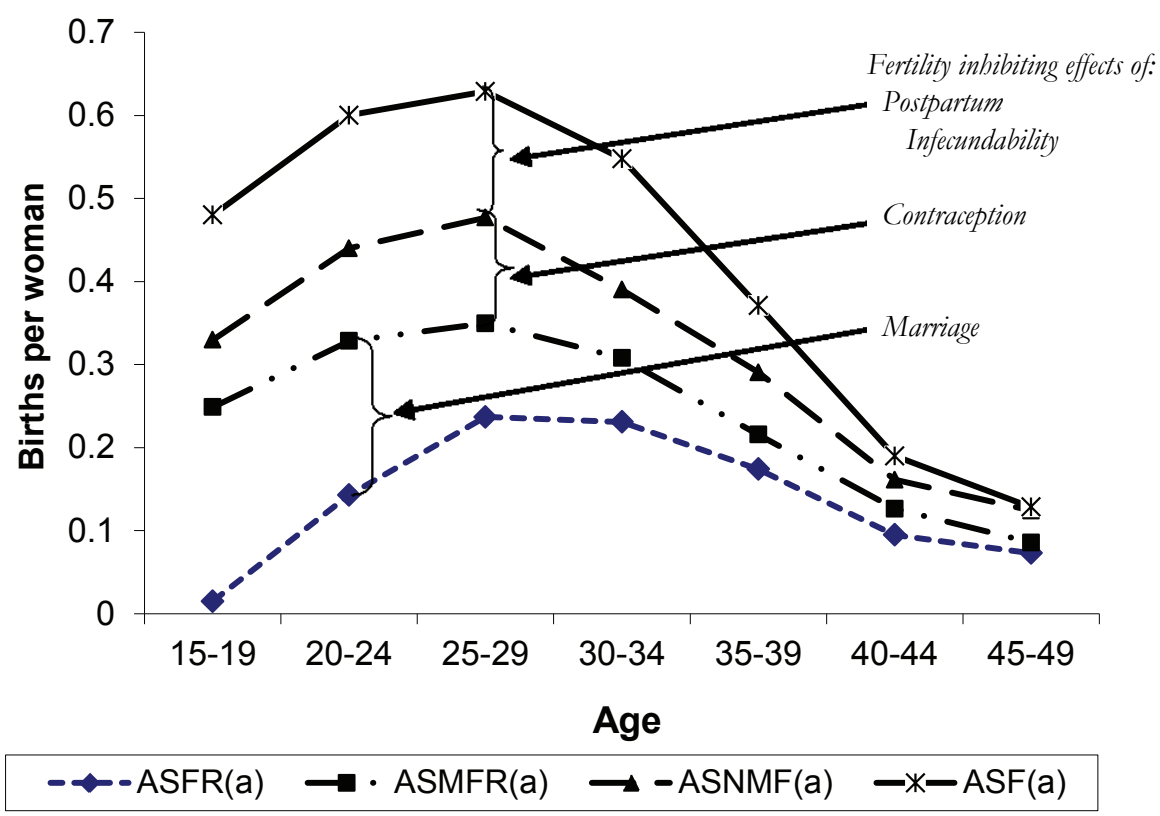

Figure 4. Age pattern of fertility inhibiting effects of marriage, contraception and postpartum infecundability measured by the observed age-specific fertility rate, ASFR(a), marital fertility rate, ASMF(a), and estimated age-specific fecundity rate, $A S F(a)$ and natural marital fertility rate $\operatorname{ASNMF}(A)$, Oman 2000.

(ASFR) is primarily due to the change in marriage pattern and prevailing long duration of post-partum infecundability associated with long duration of breastfeeding and post-partum abstinence. Contraception has also played an important role in fertility reduction in recent times. The recent fertility decline in Oman can be attributed to deliberate marital fertility control, due to the rising age at marriage and increased contraceptive use. Data from the last few national-level surveys also support this conclusion. Like other Muslim countries, such as in Iran (Erfani and McQuillan 2008), marriage is the only legally and socially acceptable way to both initiate sexual activity and start childbearing in Omani society. A delay in marriage, therefore, would play a key role in constraining fertility. Figure 4 clearly shows the substantial reduction in marital fertility among women under age 30 that is due to postponement of marriage.

Oman has a long tradition of early marriage and universal marriage among the females as almost 100 percent of the women are married by age 40 . However, in recent times there has been a substantial shift towards later marriage among the females, as evidenced by decreases in the proportion of young marriages. There is a steady increase in the singulate mean age at marriage (SMAM). SMAM has increased from 19.2 years in 1988 to 22.0 years in 1995, and it further increased to 23.5 years in 2000 , a rise of 18 months within a 5 -year period.

The rising trends in age at first marriage of females can be traced from the rising trends in the proportion of singles in the younger age groups, as reported by the surveys conducted during 1988-2000 (Figure 5). It is clear from Figure 4 that the proportion of single females of reproductive age doubled (from 18 per 


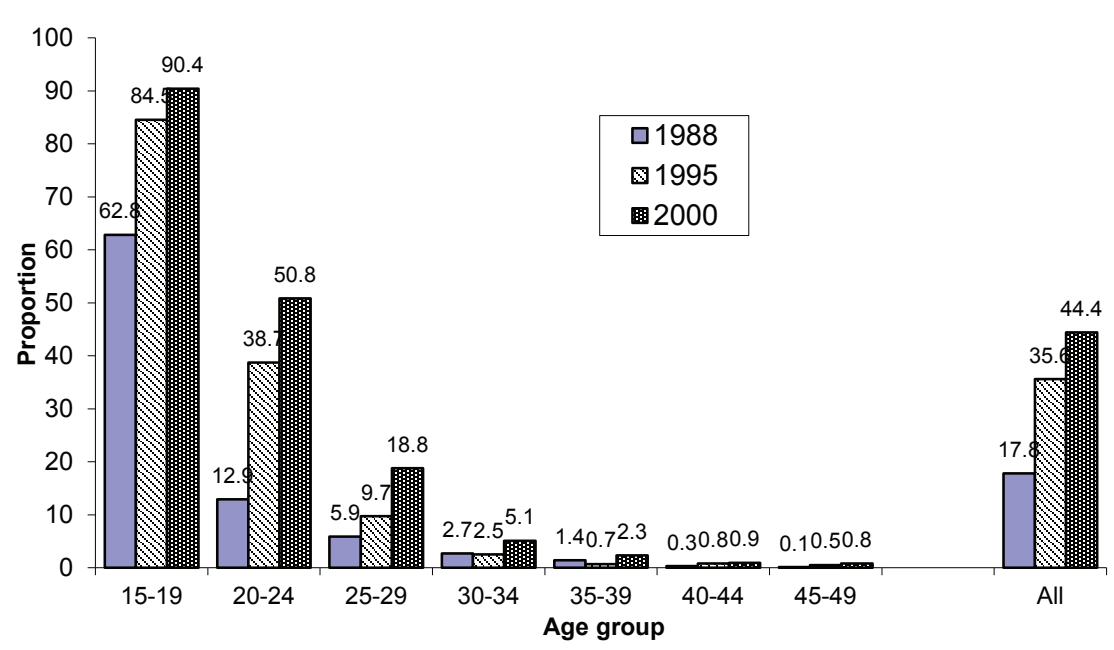

Figure 5. Proportion of single women by age at different time point: 1988-2000.

cent to 36 per cent) between 1988 and 1995, and the figure reached 44 percent by 2000. Over the period, the proportion of single women increased in almost all age groups. The most remarkable rise occurred in the younger age groups, particularly in the age groups 15-19 years through 25-29 years. For example, the proportion of single women in the 20-24 age group increased from 13 percent in 1988 to 51 percent in 2000 .

The contraceptive prevalence rate also increased by more than three times since the late 1980s, from 8.6 percent in 1988 to 31.7 percent in 2000 (Figure 6). Figure 6 shows the percentage of contraceptive use among married women across different age groups, as reported in the three surveys of 1988, 1995, and 2000. Contraceptive use was found to be highest among women in age groups 25-29 through 35-39. Both the survey results show a similar age pattern of contraceptive use in Oman. Contraceptive use rate shows an increasing trend in all the age groups. For example, contraceptive use increased from 2.7 percent in 1988 to 21.1 percent in 2000 among adolescent girls of age 15-19, and increased from 7.1 percent in 1988 to 30 percent in 2000 among women aged 40-44.

\section{Effects of Socioeconomic Factors on Fertility}

The level of fertility and its major proximate determinants are likely to be influenced by a number of socioeconomic and cultural factors. A number of factors affecting fertility can be classified as socioeconomic determinants, namely, rural and urban area of residence, education, and work status. Survey research conducted in most countries have shown a wide gap in total fertility between rural and urban areas.

We have analyzed the effects of some selected socioeconomic variables on fertility with the help of multivariate analysis, using the 2000 National Health Survey data. The number of ever-born children has been considered as the outcome (or response) variable for fertility level, while the following have been considered 


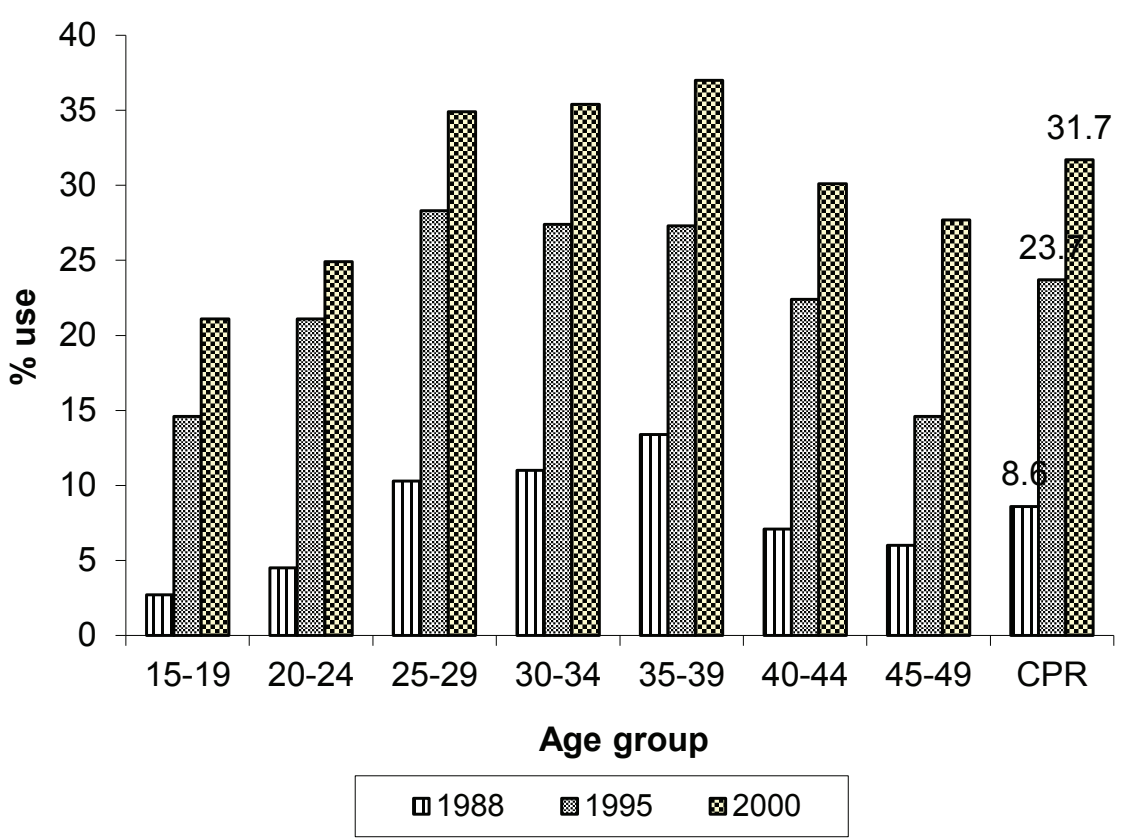

Figure 6. Percentage of currently married women using family planning methods, according to age groups and survey years, Oman 1988, 1995 and 2000.

as predictor variables: urban/rural place of residence; women's education level, categorized as illiterate, some primary, primary or preparatory, and secondary and above; women's workforce participation (work for cash or not); age at marriage, categorized as <15, 15-18, 19-22, and 23+; and any ever-used family planning methods. Since our response variable is a quantitative variable and all the predictor variables are categorical variables, represented by dummy variables, the Multiple Classification Analysis (MCA) model is the most suitable multivariate technique for identifying the independent effects of the predictor variables or the response variables before and after adjustment for its inter-correlations with other predictors in the analysis. It also provides information about the bivariate and multivariate relationships between the predictors and the dependent variable. The MCA technique can be considered the equivalent of a multiple regression analysis using dummy variables (Retherford and Choe 1993). MCA produces the same overall results as multiple regression with dummy variables, although there are differences in the way the information is reported. For example, an MCA in SPSS produces an analysis of variance with the appropriate $\mathrm{F}$ tests, decomposing the sums of squares explained by the model into the relative contributions of the factor of interest. Tables 4 and 5 present the results of MCA of the factors affecting fertility in Oman.

The one-way analysis of variance results in Table 4 indicate that women's age at marriage, education, and contraceptive use have significant effects on fertility. Women's work status has some marginal effect on fertility in Oman, while urban/ rural place of residence do not have any significant effect on fertility. It was commonly held that fertility levels fell consistently with increasing levels of education, a demographic transition that was concurrent with the process of socioeconomic 
Table 4. Analysis of Variance (ANOVA) Table showing the factors affecting the fertility (number of children ever born), Oman 2000.

\begin{tabular}{lrrrrr}
\hline \multicolumn{1}{c}{ Source of variation } & Sum of Squares & df & Mean Square & \multicolumn{1}{c}{ F } & P-value \\
\hline Age at marriage & 3631.56 & 3 & 1210.52 & 110.21 & .000 \\
Place of residence & .05 & 1 & .05 & .00 & .948 \\
Women education & 651.03 & 3 & 217.01 & 19.75 & .000 \\
Ever used contraceptives & 65.56 & 1 & 65.56 & 5.96 & .015 \\
Work for cash & 36.94 & 1 & 36.94 & 3.36 & .067 \\
Combined effects & 4385.14 & 9 & 487.23 & 44.36 & .000 \\
Residual & 15047.66 & 1370 & 10.98 & & \\
\hline Total & 19432.80 & 1379 & 14.09 & & \\
\hline
\end{tabular}

development in many countries. Similarly, many studies have shown that women's work status has a negative relationship with fertility.

The MCA results in Table 5 show that among the selected factors, women's age at marriage is the most influential factor determining the number of children ever born, as indicated by the highest value of the bivariate correlation ratio $E t a=0.432$ and the adjusted multivariate correlation ratio Beta $=0.400$. As expected, age at marriage shows a negative effect on fertility. For example, women with age at marriage of less than 15 are twice as likely to have a higher than average number of children than women with age at marriage of 23 years or more. Women's education is also a very influential factor determining the number of children ever born $(E t a=0.260$ and Beta $=0.201)$. Number of children ever born decreases with the level of education. The relationship between education and fertility has been a recurrent theme in the demographic literature. Educational attainment is thought to affect both the quantum and the tempo of fertility, partly by postponing age at

Table 5. Multiple Classification Analysis (MCA) of fertility, Oman 2000.

\begin{tabular}{|c|c|c|c|c|c|}
\hline \multirow[b]{2}{*}{ Vaiables } & \multirow{2}{*}{$\mathrm{N}$} & \multicolumn{2}{|c|}{ Predicted Mean } & \multicolumn{2}{|c|}{ Correlation ratio } \\
\hline & & Unadjusted & $\begin{array}{l}\text { Adjusted for } \\
\text { factors }\end{array}$ & $\begin{array}{l}\text { Unadjusted } \\
(\eta)\end{array}$ & $\begin{array}{c}\text { Adjusted } \\
\text { for factors }(\beta)\end{array}$ \\
\hline Age at marriage & & & & 0.432 & 0.400 \\
\hline$<15$ & 400 & 7.07 & 6.88 & & \\
\hline $15-18$ & 568 & 4.78 & 4.82 & & \\
\hline $19-22$ & 264 & 2.93 & 3.09 & & \\
\hline $23+$ & 148 & 2.71 & 2.78 & & \\
\hline Place of residence & & & & 0.034 & 0.007 \\
\hline Urban & 994 & 4.79 & 4.88 & & \\
\hline Rural & 386 & 5.07 & 4.83 & & \\
\hline Women education & & & & 0.260 & 0.201 \\
\hline Illiterate & 512 & 5.99 & 5.79 & & \\
\hline Some primary & 238 & 4.94 & 4.82 & & \\
\hline Primary/Preparatory & 386 & 4.28 & 4.29 & & \\
\hline Secondary+ & 244 & 3.38 & 3.90 & & \\
\hline Ever use contraceptive & & & & 0.050 & 0.058 \\
\hline Yes & 444 & 5.14 & 5.18 & & \\
\hline No & 936 & 4.74 & 4.72 & & \\
\hline Work for cash & & & & 0.036 & 0.048 \\
\hline Yes & 166 & 4.51 & 5.35 & & \\
\hline No & 1214 & 4.92 & 4.80 & & \\
\hline
\end{tabular}


marriage and partly by working through several proximate determinants leading to later family formation, (Boongaarts 1978; Martin 1995). These include efficacy of fertility planning and control resulting in fewer unwanted births. Education also alters demand for additional children. Ever used contraceptive methods and women's work status also play important roles in determining the number of children ever born. The effects of these variables even increases after controlling for other variables. Although urban women have a slightly lower average number of children than their rural counterparts, it becomes less important when other socioeconomic factors are controlled.

\section{Discussion and Conclusion}

The objective of this study was to analyze current fertility trends in Oman and examine the role of proximate determinants in determining fertility levels in Oman. The analysis reveals that there has been a dramatic fall in the level of fertility in recent years in Oman. Fertility has declined from a very high rate of 8.6 births per woman in 1988 to 7.1 births per woman in 1995, which further declined to 5.1 births per woman in 2000 — that is, a decline of three and a half births per woman, or a decline of 41 percent of total fertility over a period of twelve years. The declining trends in fertility are also evident from the analysis of the fertility rates by age cohort, as reflected in the three national-level surveys conducted in 1988, 1995, and 2000. The age-specific fertility rates declined for all the age groups except the two older-age groups (40-44 and 45-49). Fertility decline is steeper among the young women under age 30 . The relative contribution to total fertility by women under age 25 declined from 35 percent in 1988 to 12 percent in 2000. This indicates that there is a shift in the tempo of fertility towards higher age groups. The shift in timing in fertility to older ages is evident from the rising mean age at first birth, due to rise in mean age at marriage. As the desired family size is still very high (5.5 children) and the age at marriage is rising, couples tend to achieve their desired number of children by continuing fertility until the end of the reproductive period.

Our empirical analysis focused on the relative contributions of the three most important proximate determinants of fertility: the proportion married, use of contraception, and post-partum infecundability. The analysis suggests that until 1995, the lactational infecundability pattern, closely followed by marriage, played the most prominent part in reducing natural fertility. Contraception had the next most important fertility inhibiting effect. However, the most recent survey results show that the marriage pattern has emerged as the most prominent inhibitor of fertility in Oman, with post-partum infecundability the second most important fertility inhibitor and contraception the third. Marriage contributes 38 per cent of the total reduction of current fertility, while post-partum infecundability contributes 33 per cent of the total reduction of fertility and contraception contributes 29 per cent.

The fertility-inhibiting effect of postpartum infecundability as found in Oman is similar to the pattern found in most traditional societies (Erfani and McQuillan 2008). This is a consequence of the universal breast-feeding found in Oman. Both culture and the current health policy in Oman favor universal and prolonged lactation which improve both the health condition of children and the widening 
of birth intervals. However, recent survey results recorded declining trends in the duration of both breastfeeding and post-partum amenorrhea. Modernization and increased use of contraception might be related to the declining trends in breastfeeding and post-partum amenorrhea. Other studies (Salway et.al. 1993) identified increased use of contraception as the most important determinant for the declining trend in post-partum amenorrhea.

Although contraception has the least fertility-reducing effects among the three proximate determinants, it is not insignificant, and the fertility inhibiting effects of contraception are increasing with the rising trends in the use of modern contraceptive methods. The contraceptive prevalence rate has increased remarkably, from 8 percent in 1988 to 32 percent in 2000. The method mix that has been developed over the period is also remarkable. A large proportion of women are using highly effective semi-permanent methods, such as IUD and injectables, and permanent methods such as female sterilization. According to the ONHS-2000, female sterilization accounts for 17 percent of the total use, while IUD and injectables constitute 36 percent of the total use (Al-Riyami et al 2000: 77). This pattern indicates that a large proportion of users are using family planning methods, not only to space but also to limit fertility. It may be generally argued that free medical care, generous social services, and free education may encourage couples to continue to have large families and high fertility. However, the prevailing reproductive behaviour and trends in fertility do not support this argument. The fact is that rapid socioeconomic development and increased female empowerment may have created a new outlook and ideas about lifestyles, leading to a decline in fertility. Thus, the decline in fertility in Oman in recent times may be related to social, health, and economic development, which through a variety of mechanisms, reduces the fertility desire and increases the fertility regulation through a synchronization of "delaying, limiting, and spacing" of births. But, due to data limitation of the surveys considered in this study, we could not test the hypothesis regarding the effects of economic development and female empowerment on fertility in Oman. However, it is clear from the analysis of proximate determinants of fertility that the delay in childbearing through the increase in age at marriage for women, and spacing and limiting births through increased use in contraception among younger women, are the most instrumental factor in the current decline in fertility in Oman.

From the foregoing analysis, it may be noted that in recent years the marriage pattern has emerged as the highest fertility-reducing factor in Oman. Until 1995, post-partum infecundability was considered to be the strongest fertility reducing factor, but by 2000 the marriage factor became the most important determinant of fertility, and its fertility inhibiting effect is increasing. On the other hand, the fertility-reducing effect of post-partum infecundability is gradually decreasing, owing to the declining trend in the duration of the post-partum amenorrhea period. It may also be mentioned here that although there is an increasing trend in the impact of the marriage factor, the prevailing cultural and social norms in Oman are unlikely to permit a change in the proportion of non-marrieds beyond a certain limit. Under these circumstances, it may be concluded that future fertility trends in Oman will largely depend on the effectiveness of contraception. 


\section{Acknowledgments}

The authors would like to thank the Ministry of Health of Oman, especially the director of planning and research, for providing the raw data files of the 1995 OFHS and 2000 NHS of Oman to conduct this study. Additional thanks go to the two anonymous reviewers for their helpful comments on earlier versions of the manuscript.

\section{References}

Al-Riyami, A, and M. Afifi. 2003. Determinants of women's fertility in Oman. Saudi Medical Journal 24(7):748-53.

Al-Riyami, A., M. Afifi, H. Al-Kharusi, and M. Morsi. 2000. National Health Survey, 2000. Vol. 2, Reproductive Health Survey. Muscat (Oman): Ministry of Health.

Bongaarts, J. 1978. A framework for the analysis of the proximate determinants of fertility. Population and Development Review 4(1):105-32.

Bongaarts, J. 1982. The fertility inhibiting effects of the intermediate fertility variables. Studies in Family Planning 13(6/7):179-89.

Bongaarts, J., and R.G. Potter. 1983. Fertility, biology and behaviour: Analysis of the proximate determinants of fertility. New York: Academic Press.

Bongaarts, J., and S.C. Watkins. 1996. Social interactions and contemporary fertility transitions. Population and Development Review 22(4):639-82.

Caldwell, J.C., B.-E. Khuda, B.C. Caldwell, I. Pieris, and P. Caldwell. 1999. The Bangladesh fertility decline: An interpretation. Population and Development Review 25(1):67-84.

Cleland, J. 1994. Fertility levels and trends in Bangladesh, in Bangladesh Fertility Survey, 1989: Secondary Analysis, edited by J. Cleland et al. Dhaka (Bangladesh): National Institute of Population Research and Training (NIPORT).

Erfani, A., and K. McQuillan. 2008. Rapid fertility decline in Iran: Analysis of intermediate variables. Journal of Biosocial Science 40:459-74.

Elttigani E. 2001a. Childbearing in five Arab countries. Studies in Family Planning 32(1):17-24.

- 2001b. Levels and Trends in Fertility in Oman and Yemen. United Nations Population Division, UN/POP/PFD/2001/8. New York: UNFPA.

Freedman, R. 1979. Theories of fertility decline: A reappraisal, in World Population and Development: Challenges and Prospects, edited by P.M. Hauser. New York. p. 63.

Martin, T.C. 1995. Women's Education and Fertility: Results from 26 Demographic and Health Surveys. Studies in Family Planning 26:187-202.

Oman Ministry of Health. 2009. Annual Health Report 2008. Muscat (Oman): Ministry of Health.

Retherford, R.D., and M.K. Choe. 1993. Statistical Models for Causal Analysis. New York: John Wiley.

Salway, S., N.C. Roy, and M.A. Koenig. 1993. Levels and Trends in Post-partum Amenorrbea, Breastfeeding, and Birth: Results from WFS surveys. WFS Comparative Studies 40. Voorburg (Netherlands): ISI.

Simmons, G.B. 1985. Theories of fertility, in Fertility in Developing Countries: An Economic Perspective on Research and Policy Issues, edited by G.M. Farooq and G.B. Simmons. London: Macmillan Press.

Sulaiman, A.J.M., A. Al-Ghassany, and S. Farid. 1992. Oman Child Health Survey 1988-89. Muscat (Oman): Ministry of Health.

Sulaiman, A.J.M., A. Al-Riyami, and S. Farid. 2000. Oman Family Health Survey 1995: Final Report. Muscat (Oman): Ministry of Health.

Tabutin, D., and B. Schoumaker. 2005. The demography of the Arab world and the Middle East from the 1950s to the 2000s. Population-E 60(5-6):505-616. 
UNDP (United Nations Development Programme). 1998. Human Development Report, 1998. New York: Oxford University Press.

United Nations. 1961. The Mysore Population Studies. ST/SOA/Ser. A/34. New York: United Nations.

- 2000. Global Population Policy Database, 1999. New York: United Nations Population Division.

Wang, S.X., Y.-D. Chen, H.C. Charles, R.W. Chen, L.P. Chow Rochat, and R.V. Rider. 1987.

Proximate determinants of fertility and policy implementation in Beijing. Studies in Family Planning 18:222-8.

Westoff, C.F. 1990. Reproductive intentions and fertility rates. International Family Planning Perspectives 16(3):84-9.

Zurayk, H. 1979. The changing role of Arab women. Population Bulletin of the United

Nations Economic Commission for Western Asia 17. 